\title{
XXVII. On endless availability; and on a restriction to the application of Carnot' principle
}

\section{Charles V. Burton D.Sc.}

To cite this article: Charles V. Burton D.Sc. (1889) XXVII. On endless availability; and on a restriction to the application of Carnot' principle , Philosophical Magazine Series 5, 28:172, 185-189, DOI: $10.1080 / 14786448908619856$

To link to this article: http://dx.doi.org/10.1080/14786448908619856

曲 Published online: 08 May 2009.

Submit your article to this journal $[\pi$

Џll Article views: 2

Q View related articles $\square$ 


\section{$\left[\begin{array}{ll}185 & ]\end{array}\right.$}

XXVII. On Endless Availability; and on a Restriction to the Application of Carnot's Principle. By CharLes V. BURTON, D.Sc.*

T $\mathrm{N}$ the following pages some experiments are described which appear to be in obvious disagreement with the Second Law of Thermodynamics. The first apparatus used is shown in fig. 1. A piece of glass tube, $\mathrm{A}$, is closed below by a dialysing membrane, $\mathrm{B}$, tied over it in the usual manner. It contains a solution to be dialysed, and is supported within a beaker, C, by wedges of cork, D, E. The beaker, C, stands on a glass plate, $\mathbf{F}$, the whole being covered by a bell-jar, $\mathrm{GH}$, which is luted with wax round the edge, $K L$, so that evaporation from the solution in the dialyser is prevented as far as possible. The beaker, $\mathrm{C}$, is at first empty; and when a certain portion of the solution in $\mathrm{A}$ has passed into

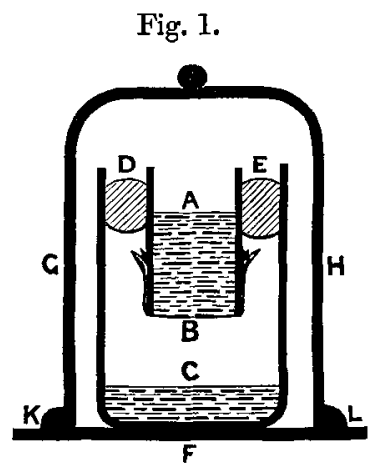
it through the membrane $\mathrm{B}$, the process is stopped by taking the apparatus to pieces and mixing the solutions. A thermometer measures the rise or fall of temperature which ensues.

Experiment I.-A saturated solution of normal sodium sulphate $\left(\mathrm{Na}_{2} \mathrm{SO}_{4}, 10 \mathrm{H}_{2} \mathrm{O}\right)$ was placed in the dialyser, together with a crystal of the salt. Contrary to anticipation, it was found after some days that the crystal had entirely disappeared and about $\frac{3}{4}$ of the solution had passed through the dialyser. When the experiment had lasted 14 days, about $\frac{5}{6}$ of the solution had passed through. The solutions in $\mathrm{A}$ and $\mathrm{C}$ were then mixed, and the temperature rose $1^{0.2}$ (Centigrade). By next day some crystals had been deposited from the mixed solutions; and had this crystallization taken place under adiabatic conditions, there must have been a further elevation of temperature. The following are the details of the experiment:-

1888. Oct. 26 ; 5.10 P.M. Solution of sodium sulphate saturated at $15^{\circ}$, together with a crystal of the salt, placed in dialyser and completely protected from evaporation.

Nov. $9 ; 4.5$ P.M. About $\frac{5}{6}$ of the solution has passed through ; no crystal remains. 
Temp. of thermometer, which has lain

beside the apparatus for 14 days $\quad \cdot=14 \cdot 2$

Temp. of solutions in $A$ and in $O . . \quad=14 \cdot 2$

Temp. of solutions after mixing . . . $=15 \cdot 4$

Rise of temperature . . . . . . . $=1 \cdot 2$

Nov. 10. Crystals, apparently about equal to the original crystal in A, have been deposited.

Thus we can perform a complete cycle of changes. Starting with saturated solution and crystals of sodium sulphate in the dialyser, at the temperature of surrounding objects, an isothermal change first takes place. Next the separated portions of the solutions are mixed, and may be maintained under adiabatic conditions till all possible crystallization has taken place, evaporation being of course excluded. The result is a considerable rise of temperature, with corresponding gain of motivity; and finally, when the liquid has been cooled down (with further deposition of crystal) to the initial temperature, we have come back to precisely the conditions with which we started--a saturated solution and crystals of sodium sulphate, at the temperature of surrounding objects.

Now consider what is the action of the dialysing membrane. According to the view of Arrhenius, dissociation and recombination are continually occurring amongst the molecules of the solution, each dissociation being accompanied by an absorption of heat, and each recombination by an equal evolution of heat. By filtering such a solution through a membrane, the equilibrium of these processes is disturbed. The various chemical constituents will pass through at different rates, thus giving rise to chemical separation and (isothermal) absorption of heat*. The membrane then plays the part of a sieve : it does not really cause dissociation; it only effects a selective distribution of molecules already dissociated. If reliance could be placed in the constancy of a dialysing membrane, and if the composition, temperature, and level of the liquid above the membrane were also maintained constant, an analysis of the portion which passes through might furnish some conclusions as to the amount of dissociation in the solution. It would be interesting to compare such results with the data afforded by measurements of electrolytic conductivity.

Experiment II.-The acid sodium sulphate being more soluble than the normal sulphate, the more acid liquid which

* The solution remaining in the dialyser is alkaline, and therefore nonsaturated; hence the crystal dissolves. 
Restriction to the Application of Carnot's Principle. $\quad 187$ passes through the dialyser will be able to dissolve some more sodium-sulphate crystals. The apparatus (fig. 1) was accordingly arranged with excess of crystals in the beaker $\mathrm{C}$, as well as in the dialyser $A$. The following are the details of the experiment :-

1888. Nov. 20 ; 5 P.M. Dialyser set up with 3 layers of parchment-paper and excess of crystals $\left(\mathrm{Na}_{2} \mathrm{SO}_{4}, 10 \mathrm{H}_{2} \mathrm{O}\right)$ in both $\mathrm{A}$ and $\mathrm{C}$. Saturated sodium-sulphate solution in $\mathrm{A}$. Apparatus completely protected from evaporation.

Dec. 5 ; 4 P.M. Temp. of solutions (before mixing) $=14^{\circ} .4$.

On pouring both solutions into a stoppered bottle which bad lain some days beside the apparatus, the temp. rose to $15^{\circ} \cdot 2$.

Rise of temperature $=0^{\circ} .8$.

Bottle now stoppered (one mgrm. sodium-sulphate crystals added to promote further crystallization).

Dec. 10. Crystals have formed in the bottle.

Temp. of solution . . . $=14^{0.2}$

Mass of solution . . . $=26 \cdot 156$ grams

Mass of crystals . . . $=2 \cdot 446$ "

Now I find the latent heat of solution of crystallized sodium sulphate to be $64 \cdot 6$, and the specific heat of a saturated solution at $15^{\circ}$ about $\cdot 97$; so that if the mixed solutions had been kept under adiabatic conditions while the crystals were forming, there would have been a total rise of temperature of more than 3 degrees (due allowance being made for the increased solubility at higher temperatures).

The mechanical availability would then be

$$
\mathrm{J} \int_{273+14 \cdot 4}^{273+17^{\cdot 4}} \frac{k \cdot \mathrm{M} \cdot(\theta-\overline{273+14 \cdot 4}) d \theta}{\theta},
$$

where $M$ is the mass of the substance, and $k$ its specific heat at the temperature $\theta$. Putting

$$
k=\text { constant }=\cdot 97,
$$

the above expression becomes

$$
\begin{aligned}
.97 \times \mathrm{JM}\left\{(290 \cdot 4-287 \cdot 4)-287 \cdot 4 \log _{e} \frac{290 \cdot 4}{287 \cdot 4}\right\} \\
=\text { about } 500,000 \mathrm{M} \text { ergs. }
\end{aligned}
$$

That is, after descending under gravity through an average height of about $2 \mathrm{~cm}$., the solution has increased the motivity of the system by an amount sufficient to raise itself vertically through more than 5 metres. 
Experiment III.-The apparatus was arranged as follows:A beaker, A (fig. 2), contained saturated solution and crystals of sodium sulphate, in which some parchment-paper, C, was partly immersed, so as to increase the surface for evaporation; A was placed within a larger beaker, $\mathrm{B}$, which was closed by a glass plate, D, luted on with soft wax so as to be air-tight. The apparatus was left in a dark corner, and after a day or two, dew was seen to have collected on the sides of

Fig. 2.

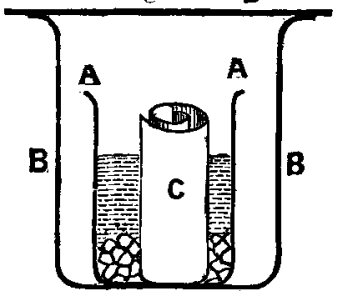
the outer beaker, B. After six weeks, about half a gram of water had collected in the beaker.

Now, undoubtedly the apparatus underwent changes of temperature; but these would be essentially very slow, so that the difference of temperature between one part of the apparatus and another would be extremely small, and this must have been especially the case between the surface of the solution and the adjacent walls of the beaker $A$, where dew had also formed and gradually inereased in amount.

From the continued distillation it seemed probable that the vapour-pressure over thoroughly saturated sodium-sulphate solution is slightly greater than over pure water. It is evident that the saturated solution has the smaller latent heat of vaporization, since evaporation is then always accompanied by crystallization. Hence a water-molecule expends less energy in attaining the gaseous state than would be the case at the surface of pure water.

Here, again, we can perform a complete cycle of operations. The water which has distilled may be collected, and the deposited crystal dissolved in it. A fall of temperature will result, which will render some of the heat of surrounding objects available for mechanical work. When the resulting solution has been raised to its previous temperature, it will just be saturated ; and on pouring it back into the beaker A, the initial conditions are exactly restored.

A direct measurement was also made of the vapour-pressure over saturated sodium-sulphate solution (without parchmentpaper). A flask containing a thick paste of sodium-sulphate solution and powdered crystals was immersed in a bath of water, and was connected by a rubber tube to a Sprengel pump and a barometer-tube. The vapour-pressure at $12^{\circ} .72$ was found to be $10.7 \mathrm{~mm}$., which differs from the vapourpressure over pure water at the same temperature by only 
about $-0.2 \mathrm{~mm}$.; while Wüllner* found for a (non-saturated) 15 -per-cent. solution of sodium sulphate at $26^{\circ} \cdot 3$, a vapourpressure $1.2 \mathrm{~mm}$. less than that of pure water. Hence it seems that, just at the point where the solution becomes fully saturated, there is a discontinuity in its vapour-pressure.

According to Regnault's classical researches, a vapourpressure of $10^{\circ} 7 \mathrm{~mm}$. over pure water corresponds to a temperature of $12^{\circ} \cdot 40$ (instead of $12^{\circ} \cdot 72$ ). The influence of the parchment-paper wick remains to be determined. But even should it produce no increase in the vapour-pressure, there would still be, on the whole, a considerable gain of motivity in experiment III.

In all these experiments the working substance becomes separated into two portions, which are not identical in chemical composition. I would therefore suggest this restriction, that we cannot as yet assume with certainty the truth of Carnot's Principle when chemical separation occurs between two finite portions of the working substance. Further research seems necessary before we can say whether or not this is the only exception to the truth of Carnot's Principle.

XXVIII. On Achromatic Interference-Bands. By LoRD Rayleigh, Sec. R.S., Professor of Natural Philosophy in the Royal Institution.

[Concluded from p. 91.]

\section{Airy's Theory of the White Centre.}

TF a system of interference-bands be examined through a 1 prism, the central white band undergoes an abnormal displacement, which has been supposed to be inconsistent with theory. The explanation has been shown by Airy $\dagger$ to depend upon the peculiar manner in which the white band is in general formed. Thus, "Any one of the kinds of homogeneous light composing the incident heterogeneous light will produce a series of bright and dark bars, unlimited in number so far as the mixture of light from the two pencils extends, and undistinguishable in quality. The consideration, therefore, of homogeneous light will never enable us to determine which is the point that the eye immediately turns to as the centre of the fringes. What, then, is the physical circumstance that determines the centre of the fringes?

"The answer is very easy. For different colours the bars

* Pogg. Ann. crii. p. 543.

+ Airy, "Remarks on Mr. Potter's Experiment on Interference," Phil. Mag, ii. p. 161 (1833). 